\title{
Cell Cycle Regulator p27 Mediates Body Mass Index Effects in Ovarian Cancer in FIGO-stages I-II
}

\author{
INGIRIDUR SKIRNISDOTTIR $^{1}$, HELENA AKERUD ${ }^{2}$, TOMAS SEIDAL ${ }^{3}$ and INGER SUNDSTROM-POROMAA ${ }^{1}$ \\ ${ }^{1}$ Department of Women's and Children's Health, Uppsala University, Uppsala, Sweden; \\ ${ }^{2}$ Department of Immunology, Genetics and Pathology Uppsala University, Uppsala, Sweden; \\ ${ }^{3}$ Department of Pathology, Halmstad Medical Center Hospital, Halmstad, Sweden
}

\begin{abstract}
Background/Aim: The aim of the present study was to evaluate the association between body mass index (BMI), the biomarker p27, and the clinical factors in FIGOstages I-II ovarian cancer. Patients and Methods: A total of 128 patients with ovarian cancer were included in the study. For testing differences in univariate analyzes we used the Pearson's Chi-square test and the log-rank test. For multivariate analyses the logistic regression and Cox regression models were used with recurrent disease and disease-free survival as endpoints, respectively. Results: Patients with $B M I \leq 25 \mathrm{~kg} / \mathrm{m}^{2}$ had a significantly better 5 -year disease-free survival compared with patients with $B M I>25 \mathrm{~kg} / \mathrm{m}^{2}$ in the total series of patients ( $\left.p=0.008\right)$, and in the series of patients $(n=77)$ with non-serous tumors $(p=0.047)$. Patients with $p 27$-positive non-serous tumors had higher survival compared to patients with p27-negative nonserous tumors $(p=0.020)$. Conclusion: The cell cycle regulator p 27 mediates BMI effects in ovarian cancer in FIGO-stages I-II.
\end{abstract}

Obesity is a known risk factor and poor prognostic factor for many co-morbidities including cancer (1). However, the influence of body mass index (BMI) on ovarian cancer outcomes is inconclusive $(2,3)$. One of the reasons for the discrepant findings is that associations between obesity and ovarian cancer survival may differ by stage, with decreased survival among those with localized disease (FIGO-stages III), and increased survival among those with late-stage

This article is freely accessible online.

Correspondence to: Ingiridur Skirnisdottir, Department of Women's and Children's Health Uppsala University SE-751 85 Uppsala, Sweden. Tel: +46 1861100, Fax: +46 18559775, e-mail: ingiridur.skirnisdottir@kbh.uu.se

Key Words: BMI, p27, non-serous tumors, ovarian cancer, FIGOstages I-II. disease (4). However, a meta-analysis including 14 studies concluded that obese women with ovarian cancer had a $17 \%$ worse survival compared to those of normal weight (5). In FIGO-stages I-II ovarian cancer patients, no difference was found in survival between obese and overweight patients compared with the normal and underweight patients. Furthermore, perioperative or postoperative morbidity and adjuvant oncologic treatment were not affected by BMI (6). From a further study on ovarian cancer, including 446 patients with FIGO-stages I-IV who underwent primary surgery and chemotherapy, only FIGO-stage and age were independent and significant prognostic factors. Thus, obese and overweight patients did not have a worse survival than normal weight and underweight patients. The prognostic impact of BMI on survival was noted only for the underweight patients with serous tumors (7).

Although BMI is an adequate indicator of overweight and obese patients in clinical studies, it does not reflect the obesity-induced metabolic changes that may be involved in carcinogenesis. Indeed, adipose tissue is a highly active endocrine and metabolic organ, secreting a range of proinflammatory factors, including the protein hormone leptin (8). Leptin influences cell proliferation and apoptosis in a human ovarian cancer cell line OVCAR-3 (9). Furthermore, leptin exposure lead to concomitant suppression of the cyclin-dependent kinase inhibitor p21 and p27, respectively. Thus, 1.9-fold suppression of cyclin-dependent kinase inhibitor p21 and 1.2-fold suppression of cyclin-dependent kinase inhibitor p27 have been detected (9). As wild-type p53 is a negative regulator of cell cycle control, loss of the p53 function may allow oncogenic lesions in the genome, as its pro-apoptotic regulation has been lost. Inhibitors of cyclin-dependent kinases inhibit the activities of cyclin dependent kinases such as p21 and p27, which are regulators of the cell cycle and are preventing the cell from entering the $\mathrm{S}$ phase. Defects in the genes downstream of p53, such as p27, will also cause deregulation of the cell cycle (10). Given these findings, the aim of the present study was to evaluate the effect of BMI on some biological factors, such 
as p27, and the clinical prognostic factors in early stages of ovarian cancer (FIGO-stages I-II).

\section{Materials and Methods}

In total, 128 patients out of the 140 consecutive patients with FIGOstage (1988 FIGO-staging) I-II epithelial ovarian cancer, who underwent primary surgery and post-surgical chemotherapy in the Uppsala-Örebro Medical Region during the 5-year period from January 1, 2000 to December 31, 2004, were included in this retrospective cohort study. These patients were also included in a study of BMI (6), however, without any immunohistochemistry. All samples were collected with the patients' informed consent, in compliance with the Helsinki Declaration, and used in accordance with the Swedish Biobank Legislation and Ethical Review Act, approved by the Uppsala Ethical Review Board, decision (ref. UPS03-477). Overall, 131 patients accepted to participate, and among these, three lacked information about height or weight at the start of post-surgical treatment, leaving 128 patients available for analysis.

The primary surgery was performed at nine different surgical gynecological departments and the staging procedure was undertaken at the time of primary surgery. Modified surgical staging according to the EORTC surgical staging (11) was undertaken in $37(29 \%)$ of the 128 cases, and in the remaining $91(71 \%)$ patients, surgical staging was regarded as minimal or inadequate according the same guidelines. Patients' characteristics, including age, BMI, performance status of the patients (WHO), FIGO-stage, serous/non-serous histology and types of ovarian tumors (Type I and Type II), according to combinations of histological subtype and FIGO-grade, are summarized in Table I. We categorized BMI as normal-weight and underweight $\left(<25.0 \mathrm{~kg} / \mathrm{m}^{2}\right)$ or obese and overweight $\left(\geq 25.0 \mathrm{~kg} / \mathrm{m}^{2}\right)$. All patients had chemotherapy 4-6 weeks after the primary surgery, most commonly paclitaxel $175 \mathrm{mg} / \mathrm{m}^{2}$ and carboplatin (AUC=5) at 3week intervals usually for four courses $(n=104)$, or single-drug carboplatin for 4-6 courses $(n=24)$. The mean follow-up time was 65 months (range $=5-110$ months). Survival was defined from the date of confirmed histological diagnosis after primary surgery to the date of recurrence, death, or last visit.

Sampling and tissue microarray construction of ovarian cancer tissue. The specimens were obtained from the paraffin blocks containing the embedded tumor tissue, removed from the tumor at primary surgery. After staining with hematoxylin and eosin they were classified and graded by a single pathologist. The tissue microarrays were constructed as described previous (12). In brief, tumor tissues were embedded in paraffin and $5 \mu \mathrm{m}$ sections stained with hematoxylin-eosin were obtained to select representative areas for biopsies. Core tissue biopsy specimens (diameter $0.6 \mathrm{~mm}$ ) were taken from these areas of individual donor paraffin blocks and precisely arrayed into a new recipient paraffin block with a custombuilt instrument. Tissue core specimens from 131 ovarian carcinomas were arranged in three recipient paraffin blocks. Two core biopsies were obtained from each specimen. The presence of tumor tissue on the arrayed samples was verified by hematoxylineosin-stained section by a pathologist.

Tissue microarray, immunohistochemistry, and interpretation. Five $\mu \mathrm{m}$ thick sections were cut from each multi tissue block and were put on coated slides and dried overnight at $37^{\circ} \mathrm{C}$. The sections were pre-treated by heath-induced epitope retrieval in target- retrieval solution (Dako), $\mathrm{pH}=6$ or EDTA buffer $\mathrm{pH}=9$, for $7+7$ min in microwave oven $\left(99^{\circ} \mathrm{C}\right)$. Blocking with peroxidase was performed for $5 \mathrm{~min}$. The slides were counterstained with hematoxylin for 2 min. The following monoclonal primary antibodies was used: NCLp27 (dilution 1:40; Vision Biosystems Novocastra, Newcastle, UK). The immunostainings were performed in an Autostainer automated machine (Dako) using REAL Envision detection system (Dako). The work of tissue-microarray construction was undertaken at the Department of Pathology, the University Hospital MAS in Malmö in South-Sweden, but the immunohistochemical analyses and interpretation were performed at the Department of Pathology, Halmstad Medical Central Hospital. The IHC stains were interpreted by two of the authors (IS and TS). At the time for evaluation, no information was available on the specific diagnosis and prognosis for the individual cases. A semi-quantitative analysis (13) was used and the stainings were graded as negative,,+++ , and +++ for $\mathrm{p} 27$. This marker was dichotomized (14) classified and graded by a single pathologist. The tissue microarrays were constructed as described previously and a semi-quantitative analysis of the immunohistochemistry was performed. The stainings were graded as negative,,+++ , and +++ for $\mathrm{p} 27$. This marker was dichotomized into negative and positive $(+,++,+++)$ cases. The staining for $\mathrm{p} 27$ was considered positive when strong granular staining of the nuclei and cytoplasm of the tumor cells was found. Information about the primary antibodies and immunohistochemical analyses can be found in previous studies (15-18).

Statistical analysis. The Pearson's Chi-square test was used for testing proportional differences in bivariate analyses. The survival curves were generated by using the Kaplan-Meier technique and differences between these curves were tested by the log-rank test. For multivariate analyses, logistic regression and Cox regression were used with recurrent disease and disease-free survival as endpoints, respectively. All tests were two-sided and the level of statistical significance was $p \leq 0.05$. The STATISTICA 13.3 $\left(\right.$ StatSoft $\left.{ }^{\mathrm{TM}}\right)$ statistical package was, used for the analyses.

\section{Results}

Patients. The study population included 77 Type I tumors (60.2\%) and 51 Type II tumors (39.8\%) (Table I). The majority $(84.4 \%)$ of the patients had stage I disease and the majority $(60.2 \%)$ of the tumors were classified as Type I tumors. The p27 status did not differ between serous and non-serous tumors $(p=0.608)$.

Primary cure was achieved in all 128 patients. The total number of recurrences was $34(27 \%)$, and 22 of these patients $(67 \%)$ died due to the disease. In the complete series, recurrent disease was significantly associated with FIGO substages $(p=0.0005)$, FIGO-grade $(p=0.030)$, and adequate surgical staging $(p=0.033)$. In the complete series, the 5 -year disease-free survival rate was $68 \%$, the disease-specific survival rate $76 \%$, and overall survival rate was $71 \%$.

Clinical features according to BMI. Some clinical and pathological features for the total series of patients were compared according to BMI strata (Table II). Thus, 
Table I. Patient characteristics $(N=128)$.

\begin{tabular}{lc}
\hline Age (median) & 59.0 years \\
BMI & $69(53.9)$ \\
BMI 25 & $59(46.1)$ \\
BMI>25 & \\
WHO performance status & $34(26.8)$ \\
0 & $66(52.0)$ \\
1 & $21(16.5)$ \\
2 & $6(4.7)$ \\
3 & \\
FIGO-stage & $44(34.4)$ \\
IA+B & $64(50.0)$ \\
IC & $20(15.6)$ \\
II & \\
Histopathology* & $49(39.2)$ \\
Serous ovarian tumors & $77(60.8)$ \\
Non-serous ovarian tumors & $20(26.0)$ \\
Mucinous & $41(53.2)$ \\
Endometrioid & $16(20.8)$ \\
Clear cell & \\
Types of ovarian tumors** & $77(60.2)$ \\
Type I tumors & 13 \\
Low-grade (G1) serous & 20 \\
Mucinous (G1+G2+G3) & 28 \\
Low-grade endometrioid (G1+G2) & 16 \\
Clear cell & $51(39.8)$ \\
Type II tumors & 36 \\
High-grade (G2+G3) serous & 13 \\
High-grade (G3) endometrioid & 2 \\
Anaplastic & \\
\hline
\end{tabular}

*Histopathology (the two tumors of anaplastic histology were not included). **Tumors divided in Type I and Type II according to combination of histological subtype and FIGO-grade.

overweight and obese (BMI >25.0) patients were older $(p=0.005)$ and more frequently had tumors of lower grade $(\mathrm{G} 1+\mathrm{G} 2)$ compared to normal and underweight (BMI $\leq 25.0)$ patients $(p=0.037)$. Patients with Type I tumors had significantly $(p=0.046)$ higher BMI compared with Type II tumors. Recurrent disease was more frequently $(p=0.025)$ found among patients with Type II tumors (not shown in the table). Furthermore, recurrent disease was more frequently ( $p=0.011$ ) found among overweight and obese patients (BMI $>25.0$ ). Finally, in the survival analysis (Figure 1) for the whole series of patients $(n=128)$, normal and underweight patients (BMI $\leq 25.0$ ) had a 5-year disease-free survival of $91 \%$ compared to survival of $77 \%$ for overweight and obese patients (BMI >25.0) (Log-rank=32.920; $p=0.008)$.

\section{Biological features according to BMI groups}

The cell cycle regulator p27. Expression of the cell cycle regulator p27 in relation to clinical characteristics across the two BMI strata is demonstrated in Table III. Positivity for p27 was associated $(p=0.002)$ with normal and underweight (BMI
Table II. Clinical features compared between BMI strata.

\begin{tabular}{|c|c|c|c|}
\hline BMI strata & $\mathrm{BMI} \leq 25$ & $\mathrm{BMI}>25$ & \\
\hline $\mathrm{N}(\%)$ & $69(54 \%)$ & $59(33 \%)$ & $p$-Value \\
\hline $\begin{array}{l}\text { Age (mean) } \\
p \text {-Value }(t \text {-test })\end{array}$ & 58 years & 62 years & 0.005 \\
\hline \multicolumn{4}{|l|}{ Histopathology* } \\
\hline Serous & $27(40)$ & $22(37)$ & \\
\hline Non-serous & $40(60)$ & $37(63)$ & \\
\hline$p$-Value (Chi-squared-test) & & & 0.729 \\
\hline \multicolumn{4}{|l|}{ Tumor grade } \\
\hline $\mathrm{G} 1+\mathrm{G} 2$ & $33(48)$ & $39(66)$ & \\
\hline $\mathrm{G} 3 * *$ & $36(52)$ & $20(34)$ & \\
\hline$p$-Value (Chi-squared-test) & & & 0.037 \\
\hline \multicolumn{4}{|l|}{ Type of tumors } \\
\hline Type I & $36(52)$ & $41(69)$ & \\
\hline Type II & $33(48)$ & $18(31)$ & \\
\hline$p$-Value (Chi-squared-test) & & & 0.046 \\
\hline \multicolumn{4}{|l|}{ FIGO-stage } \\
\hline IA-IB & $25(36)$ & $19(32)$ & \\
\hline IC & $37(54)$ & $27(46)$ & \\
\hline II & $7(10)$ & $13(22)$ & \\
\hline$p$-Value (Chi-squared-test) & & & 0.180 \\
\hline \multicolumn{4}{|l|}{ Recurrent disease } \\
\hline Without & $57(83)$ & $37(63)$ & \\
\hline With & $12(17)$ & $22(37)$ & \\
\hline$p$-Value (Chi-squared-test) & & & 0.011 \\
\hline
\end{tabular}

$\leq 25.0)$ patients for all tumors $(\mathrm{N}=128)$, non-serous tumors $(p=0.004)$, Type II tumors $(p=0.044)$ and tumors without recurrent disease $(p=0.018)$. In the survival analysis of the whole series of patients $(\mathrm{N}=128)$, patients with $\mathrm{p} 27$ - positive tumors had a 5-year disease-free survival of $91 \%$ compared to survival of $79 \%$ for patients with p27-negative tumors. However, survival did not differ depending on the p27 status alone (Log-rank=31.029; $p=0.153$ ), data not shown.

Non-serous tumors. In the survival analysis of non-serous tumors, patients $(\mathrm{N}=40)$, who were normal and underweight (BMI $\leq 25.0$ ) had a better survival compared with overweight and obese patients $(\mathrm{N}=37)(\mathrm{BMI}>25.0)($ Log-rank=16.340; $p=0.047)$, data not shown.

In non-serous tumors $(\mathrm{N}=77)$ [mucinous $(\mathrm{N}=20)$, endometroid $(\mathrm{N}=41)$ and clear cell $(\mathrm{N}=16)]$ the p 27 status was compared according to BMI. In the subgroup of patients with tumors of endometroid histology, positivity for p27 was detected in 18 out of the 21 tumors $(86 \%)$ in patients with BMI $\leq 25.0$ compared with eight out of the 20 patients (40\%) with BMI >25.0 $(p=0.002)$. However, no differences according to p27 status and BMI in mucinous or clear cell tumors could be found. In a separate survival analysis 


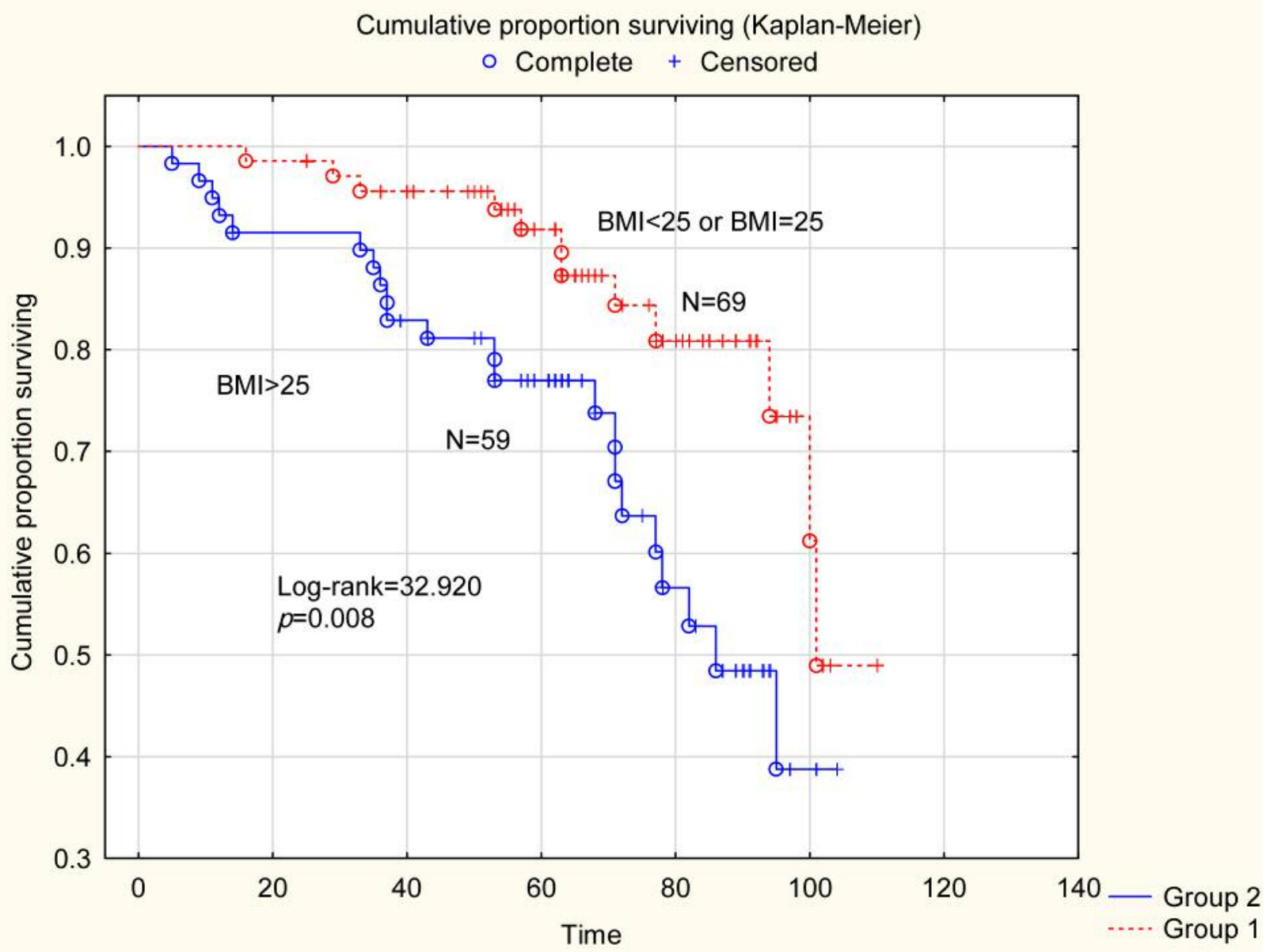

Figure 1. Survival analysis for the whole series of patients $(N=128)$. Normal and underweight weight patients had a 5-year disease-free survival of $91 \%$ compared to survival of $77 \%$ for obese and overweight patients (Log-rank=32.920; $p=0.008$ ).

(Figure 2) for the series of patients with non-serous tumors $(\mathrm{N}=77)$, patients with $\mathrm{p} 27$ positive tumors $(\mathrm{N}=42)$, had a significantly better 5 -year disease-free survival of $92 \%$ compared to $77 \%$ survival for patients $(\mathrm{N}=35)$ with $\mathrm{p} 27$ negative tumors (Log-rank=16.340; $p=0.020)$.

Serous tumors. In serous tumors $(\mathrm{n}=49), \mathrm{p} 27$ positivity did not differ between BMI groups $(p=0.237)$.

Multivariable analysis. Results for bivariate and multivariable Cox-analysis with disease-free survival (DFS) as an endpoint both for the whole series of patients $(\mathrm{N}=128)$, and one analysis limited to patients with non-serous tumors are demonstrated in Tables IV and V, respectively. In the first analysis, FIGO-stage, Type of tumor (I/II), and BMI (BMI $\leq 25$ or BMI $>25$ ) were all significant and independent prognostic factors. In the analysis of patients with non-serous tumors, the Type (I/II) of tumor was replaced by the grade $(\mathrm{G} 1+\mathrm{G} 2 / \mathrm{G} 3)$ of tumor as the Type I tumors are mostly nonserous tumors. Thus, both tumor grade and p27 status, but not BMI, were significant and independent prognostic factors for patients with non-serous tumors.

Results from bivariate and multivariable logistic regression analysis with recurrent disease as the endpoint for the whole series of patients are presented in Tables VI and VII, limited to patients with non-serous tumors $(\mathrm{N}=77)$. In the first analysis, FIGO-stage, Type of tumor (I/II), and BMI (BMI $\leq 25$ or BMI $>25$ ) were all significant and independent predictive factors for recurrent disease. In nonserous tumors (Table VII), FIGO-stage, grade of tumor and p27 status, were independent predictive factors for recurrent disease. Again, BMI did not influence the risk of recurrent disease in non-serous tumors, when p27 was also incorporated in the model. 


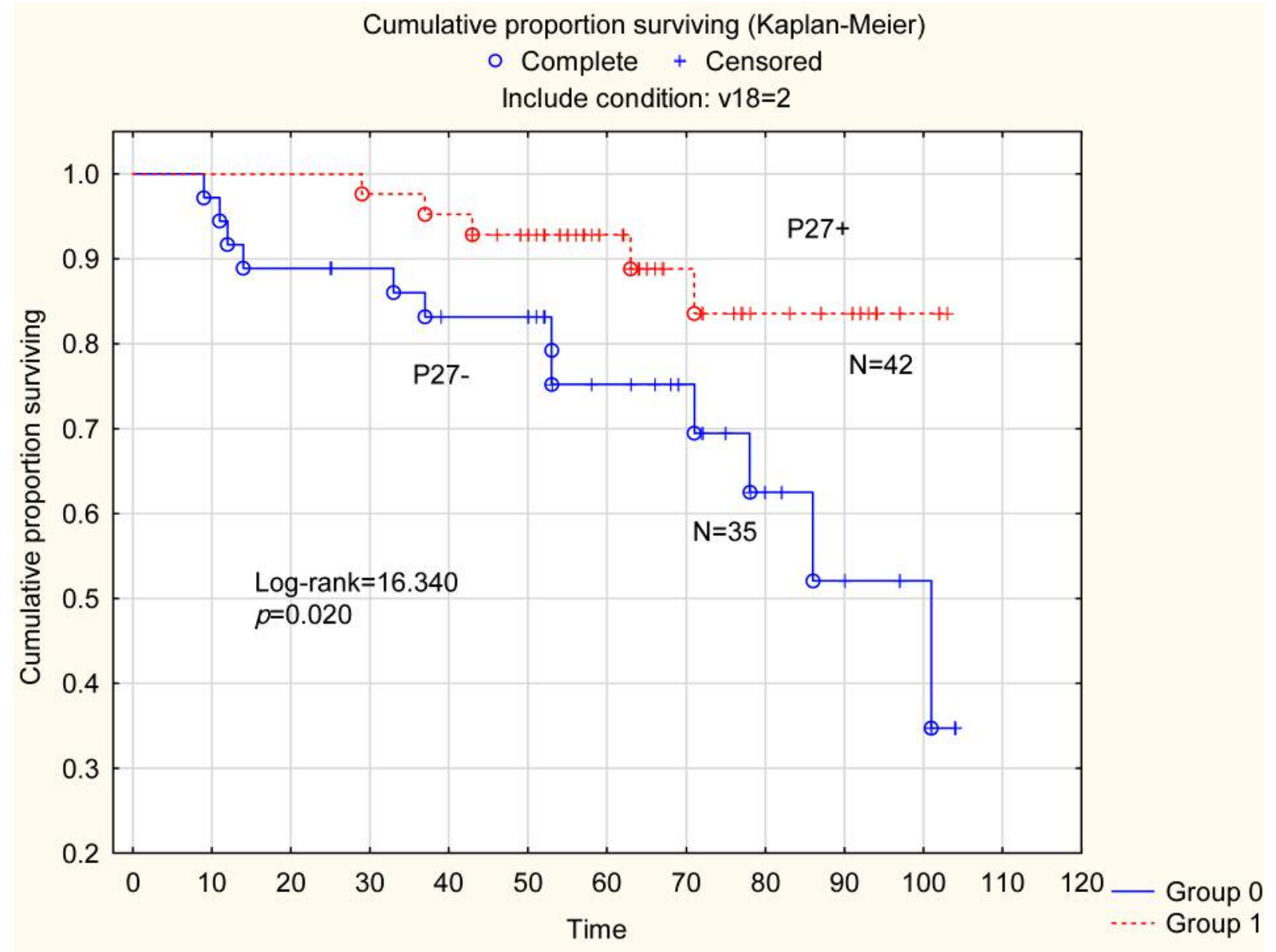

Figure 2. Survival analysis for the series of patients with non-serous tumors $(n=77)$. Patients $(n=42)$ with p27-positive tumors a significant better 5 -year disease-free survival of $92 \%$ compared to survival of $77 \%$ for patients $(N=35)$ with p27 negative tumors (Log-rank=16.340; $p=0.020)$.

\section{Discussion}

In the present study, we evaluated the relevance of BMI in relation to some clinical and pathological features, including expression of $\mathrm{p} 27$, in a series of 128 patients with epithelial ovarian cancer in FIGO-stages I-II. Normal and underweight patients had a better 5-year disease-free survival compared to obese and overweight patients in the total series of 128 patients. Further, BMI was an independent and significant prognostic factor for diseasefree survival and a significant predictive factor for recurrent disease in the overall series of tumors. Obese and overweight patients were older and more frequently had tumors of lower grade (G1 and G2) compared to underweight and normal weight patients. In the bivariate analysis of patients with non-serous tumors, BMI played a role, as normal and underweight patients had a better 5-year disease-free survival compared with obese and overweight patients. However, this effect was lost when adjusted for age, FIGO stage, grade, and p27 status.

Patients with p27 positive non-serous tumors had significantly higher disease-free survival compared with p27 negative non-serous tumors. In a Cox multivariable analysis in non-serous tumors, only tumor grade and the p27 status were independent and significant prognostic factors for survival. In addition, FIGO-stage, tumor grade and the p27 status were predictive factors for recurrent disease. In this study, all the 16 clear cell tumors were classified as grade 3 tumors and this idem could explain why in the multivariate analysis tumor grade was a significant prognostic and predictive factor only in the subgroup of non-serous tumors.

Our findings are in line with a recent meta-analysis, suggesting that obese women with ovarian cancer have worse survival compared with normal weight women (5). However, although BMI is an adequate indicator of overweight and obese patients in clinical studies, it does not 
Table III. Protein expression of p27 in tumors in the whole series in relation to different clinical and pathological subgroups in the two different BMI strata $(N=128)$.

\begin{tabular}{|c|c|c|c|}
\hline BMI strata & $\mathrm{BMI} \leq 25$ & $\mathrm{BMI}>25$ & $\mathrm{~N}(\%)$ \\
\hline $\mathrm{N}(\%)$ & $69(54)$ & $59(33)$ & $p$-Value \\
\hline All tumors & & & $(\mathrm{N}=128)$ \\
\hline p27+ & $48(70)$ & $25(42)$ & \\
\hline p27- & $21(30)$ & $34(58)$ & \\
\hline$p$-Value (Chi-squared-test) & & & 0.002 \\
\hline Non-serous tumors & & & $\mathrm{N}=77$ \\
\hline $\mathrm{p} 27+$ & $28(70)$ & $14(38)$ & \\
\hline p27- & $12(30)$ & $23(62)$ & \\
\hline$p$-Value (Chi-squared-test) & & & 0.004 \\
\hline Serous tumors & & & $\mathrm{N}=49$ \\
\hline p27+ & $18(67)$ & $11(50)$ & \\
\hline p27- & $9(33)$ & $11(50)$ & \\
\hline$p$-Value (Chi-squared-test) & & & 0.237 \\
\hline Type I tumors & & & $\mathrm{N}=77$ \\
\hline p27+ & $21(58)$ & $15(37)$ & \\
\hline p27- & $15(42)$ & $26(63)$ & \\
\hline$p$-Value (Chi-squared-test) & & & 0.056 \\
\hline Type II tumors & & & $\mathrm{N}=51$ \\
\hline $\mathrm{p} 27+$ & $27(82)$ & $10(56)$ & \\
\hline p27- & $6(18)$ & $8(44)$ & \\
\hline$p$-Value (Chi-squared-test) & & & 0.044 \\
\hline No recurrence tumors & & & $\mathrm{N}=94$ \\
\hline p27+ & $40(70)$ & $17(46)$ & \\
\hline p27- & $17(30)$ & $20(54)$ & \\
\hline$p$-Value (Chi-squared-test) & & & 0.018 \\
\hline Recurrence tumors & & & $\mathrm{N}=34$ \\
\hline $\mathrm{p} 27+$ & $8(67)$ & $8(36)$ & \\
\hline p27- & $4(33)$ & $14(64)$ & \\
\hline$p$-Value (Chi-squared-test) & & & 0.09 \\
\hline
\end{tabular}

Table IV. Cox analysis (bivariate and multivariable); prognostic factors for disease-free survival for the whole series ( $N=128$ patients).

\begin{tabular}{|c|c|c|c|c|c|}
\hline \multirow[b]{2}{*}{ Variable } & \multicolumn{2}{|c|}{ Bivariate analysis } & \multicolumn{2}{|c|}{ Multivariable analysis } & \multirow[b]{2}{*}{$p$-Value } \\
\hline & HR & $95 \% \mathrm{CI}$ & HR & $95 \% \mathrm{CI}$ & \\
\hline Age & 1.015 & $0.986-1.045$ & 1.003 & $0.969-1.038$ & 0.840 \\
\hline Stage (I/II) & 3.172 & $1.580-6.362$ & 2.362 & $1.567-4.822$ & 0.018 \\
\hline Type (I/II) & 1.976 & $1.003-3.895$ & 2.586 & $1.234-5.418$ & 0.012 \\
\hline $\mathrm{BMI}^{* *}$ & 2.507 & $1.239-5.073$ & 2.744 & $1.190-6.329$ & 0.017 \\
\hline $\mathrm{P} 27 * *$ & 0.626 & $0.319-1.270$ & 0.751 & $0.368-1529$ & 0.430 \\
\hline
\end{tabular}

$\mathrm{BMI}^{* *}(\mathrm{BMI} \leq 25$ or $\mathrm{BMI}>25) ; \mathrm{P} 27 *(\mathrm{p} 27+v s . \mathrm{p} 27-)$.

reflect the obesity-induced metabolic changes that may be involved in carcinogenesis (19). One commonly studied metabolic factor is leptin, which induces cell proliferation and angiogenesis, and inhibits apoptosis in ovarian cancer cells $(20,21)$. A previous study (22) including 161 patients
Table V. Cox analysis (bivariate and multivariable) with prognostic factors for disease-free survival for patients with non-serous tumors $(N=77)$.

\begin{tabular}{lccccccr}
\hline & \multicolumn{2}{c}{ Bivariate analysis } & & \multicolumn{2}{c}{ Multivarible analysis } & \\
\cline { 2 - 3 } Variable & HR & $95 \% \mathrm{CI}$ & & HR & $95 \% \mathrm{CI}$ & & $p$-Value \\
\hline Age & 1.015 & $0.976-1.055$ & & 1.039 & $0.968-1.114$ & 0.275 \\
Stage (I/II) & 4.223 & $1.620-11.009$ & & 2.660 & $0.906-7.809$ & 0.074 \\
Grade* & 3.520 & $1.238-10.005$ & & 4.646 & $1.519-14.205$ & 0.007 \\
BMI** & 2.740 & $0.961-7.810$ & & 1.697 & $0.496-5.800$ & 0.398 \\
P27\# & 0.308 & $0.108-0.876$ & & 0.229 & $0.075-0.706$ & 0.010 \\
\hline
\end{tabular}

*Clear cell tumors were all of Grade 3; $\mathrm{BMI}^{* *}(\mathrm{BMI} \leq 25$ or $\mathrm{BMI}>25)$; $\mathrm{P} 27 \#(\mathrm{p} 27+v s . \mathrm{p} 27-)$.

Table VI. Predictive factors for recurrent disease (bivariate and multivariable logistic regression analysis) ( $n=128$ patients).

\begin{tabular}{|c|c|c|c|c|c|}
\hline \multirow[b]{2}{*}{ Variable } & \multicolumn{2}{|c|}{ Bivariate analysis } & \multicolumn{2}{|c|}{ Multivariable analysis } & \multirow[b]{2}{*}{$p$-Value } \\
\hline & OR & $95 \% \mathrm{CI}$ & OR & $95 \% \mathrm{CI}$ & \\
\hline Age & 1.013 & $0.981-1.047$ & 1.003 & $0.963-1.045$ & 0.862 \\
\hline Stage (I/II) & 7.959 & $2.801-22.617$ & 6.239 & $2.067-19.376$ & 0.001 \\
\hline Type (I/II) & 2.456 & $1.099-5.490$ & 3.618 & $1.299-10.075$ & 0.013 \\
\hline BMI** & 2.470 & $0.130-6.830$ & 2.788 & $0.990-7.847$ & 0.049 \\
\hline P27\# & 0.570 & $0.260-1.270$ & 0.472 & $0.175-1.274$ & 0.134 \\
\hline
\end{tabular}

$\mathrm{BMI}^{* *}(\mathrm{BMI} \leq 25 v s . \mathrm{BMI}>25) ; \mathrm{P} 27 \#(\mathrm{p} 27+v s . \mathrm{p} 27-)$.

Table VII. Predictive factors for recurrent disease (bivariate and multivariable logistic regression analysis) for patients with non-serous tumors $(n=77)$.

\begin{tabular}{lccccccc}
\hline & \multicolumn{2}{c}{ Bivariate analysis } & & \multicolumn{2}{c}{ Multivariable analysis } \\
\cline { 2 - 3 } Variable & OR & 95\%CI & & OR & 95\%CI & & $p$-Value \\
\hline Age & 1.015 & $0.971-1.060$ & & 1.039 & $0.968-1.114$ & 0.275 \\
Stage (I/II) & 10.133 & $2.649-38.759$ & & 9.399 & $1.582-52.520$ & 0.009 \\
Grade* & 4.920 & $1.494-16.193$ & & 32.860 & $3.819-282.729$ & 0.001 \\
BMI & 0.131 & $0.016-1.096$ & & 3.214 & $0.550-18.766$ & 0.186 \\
P27 & 0.570 & $0.260-1.270$ & & 0.033 & $0.003-0.311$ & 0.002 \\
\hline
\end{tabular}

*Clear cell tumors were all of Grade 3.

with ovarian cancer in FIGO-stages III-IV, reported no correlation between BMI and the ratio of leptin/adiponectin, but adipose tissue produces numerous adipokines as leptin and adiponectin (8). Thus, only age and BMI were independent and prognostic factors for survival in a Cox multivariate analysis, but not tumor grade, FIGO-stage, optimal cytoreduction or the ratio of leptin/adiponectin. 
Unfortunately, no information about leptin and adiponectin was available in the present work.

Very little information is available on the relationship between obesity and p27 status. In a previous study including 174 patients with ovarian cancer in FIGO-stages I-IV (23), positivity for p27 was found in tumors of the 139 (80\%) out of 174 patients, detected by tissue microarray and immunohistochemistry. Their results could be compared to the results of our series, but positive p27 expression was found in tumors of $73(57 \%)$ out of the 128 patients included, also detected by tissue microarray and immunohistochemistry. However, no differences according to BMI, FIGO-stage, tumor grade or survival, related to p27 status of tumors were detected in their study.

In a study of 349 epithelial ovarian patients from China (24), normal weight patients usually were of younger age and were in FIGO-stages I-II at diagnosis compared with patients in FIGO-stages III-IV at diagnosis. Thus, the subgroup of the 140 patients in FIGO-stages I-II were younger, had lower BMI, higher high-density lipoprotein (HDL) and lower triglyceride (TG) levels compared with the subgroup of the resting 209 patients in FIGO-stages III-IV.

The prognostic significance of p27 alterations in relation to BMI using 630 patients of stage I-IV colon cancers have been examined in a USA study (25). Tumors limited to nuclear positivity for $\mathrm{p} 27$ were interpreted as p27 positive. Compared to the 130 patients with p27 positive colon tumors, the resting 460 patients with no p27 expression, experienced poor tumor-specific and overall mortality. By comparing colon cancer mortality in that study between obese and non-obese patients (BMI $>30) /($ BMI $\leq 30)$, it was concluded, that the effect of p27 alterations on survival, were strong among obese patients with colon cancer and the adverse effect of obesity on survival appears to be limited because of the protective effect of a positive p27 expression (nuclear p27) in colon cancer tumors. Tumors limited to nuclear p27 expression were interpreted as p27 positive. However, in the present study, the staining for p27 was considered positive when strong granular staining of both the nuclei and cytoplasm of the tumor cells was detected. In summary, as criteria for p27 positivity were different from the criteria in our study, and primary tumors were of different origin, it is difficult to compare their results with results from the present study. However, their results suggest a host-tumor interaction, where p27 appears to play a role.

In a meta-analysis on patients with ovarian cancer including 905 patients, loss of p27 was associated with a worse survival (26) Therefore, they concluded, that the development of strategies for targeting p27 could be a reasonable therapeutic approach. Furthermore, as ovarian cancer has a poor prognosis, p27 has been implicated in tumor prognosis and drug-resistance in ovarian cancer studies (26). Also, p27 was involved in chemo-resistance of
SKOV3 cells, but up-regulated p27 expression, induced by demethylation, may enhance sensitivity to cisplatin through the regulation of the cell cycle (27). Finally, results from our study could indicate that the cell cycle regulator p27 could be included in the future treatment of ovarian cancer, especially of non-serous ovarian cancer.

\section{Conflicts of Interest}

The Authors declare no conflicts of interest regarding this study.

\section{Authors' Contributions}

Conceptualization: IS, TS, HA, ISP: Data curation: IS; Formal analysis: IS, ISP; Funding acquisition: IS, ISP; Investigation: IS, TS, HA; Methodology: TS, IS

\section{References}

1 Ovarian cancer and body size: Individual participant metaanalysis including 25,157 women with ovarian cancer from 47 epidemiological studies. PLoS Med 9(4): e1001200, 2012. PMID: 21997171. DOI: 10.1097/IGC.0b013e31822d2aa3

2 Backes FJ, Nagel CI, Bussewitz E, Donner J, Hade E and Salani $\mathrm{R}$ : The impact of body weight on ovarian cancer outcomes. Int J Gynecol Cancer 21(9): 1601-1605, 2011. PMID: 26769113. DOI: $10.1007 / \mathrm{s} 11912-015-0488-3$

3 Purcell SA, Elliott SA, Kroenke CH, Sawyer MB and Prado CM: Impact of body weight and body composition on ovarian cancer prognosis. Curr Oncol Rep 18(2): 8, 2016. PMID: 28588323. DOI: $10.1038 /$ bjc.2017.162

4 Bandera EV, Lee VS, Qin B, Rodriguez-Rodriguez L, Powell CB and Kushi LH: Impact of body mass index on ovarian cancer survival varies by stage. Br J Cancer 117(2): 282-289, 2017. PMID: 28588323. DOI: 10.1038/bjc.2017.162

5 Protani MM, Nagle CM and Webb PM: Obesity and ovarian cancer survival: A systematic review and meta-analysis. Cancer Prev Res (Phila) 5(7): 901-910, 2012. PMID: 22609763. DOI: 10.1158/1940-6207.CAPR-12-0048

6 Skirnisdottir I and Sorbe B: Prognostic impact of body mass index and effect of overweight and obesity on surgical and adjuvant treatment in early-stage epithelial ovarian cancer. Int $\mathbf{J}$ Gynecol Cancer 18(2): 345-351, 2008. PMID: 17587318. DOI: 10.1111/j.1525-1438.2007.01013.x

7 Skirnisdottir I and Sorbe B: Body mass index as a prognostic factor in epithelial ovarian cancer and correlation with clinicopathological factors. Acta Obstet Gynecol Scand 89(1): 101-107, 2010. PMID: 19878086. DOI: $10.3109 / 00016340903322735$

8 van Kruijsdijk RC, van der Wall E and Visseren FL: Obesity and cancer: The role of dysfunctional adipose tissue. Cancer Epidemiol Biomarkers Prev 18(10): 2569-2578, 2009. PMID: 19755644. DOI: 10.1158/1055-9965.Epi-09-0372

9 Ptak A, Kolaczkowska E and Gregoraszczuk EL: Leptin stimulation of cell cycle and inhibition of apoptosis gene and protein expression in ovcar-3 ovarian cancer cells. Endocrine 43(2): 394-403, 2013. PMID: 22968658. DOI: 10.1007/s12020-012-9788-7

10 Foster I: Cancer: A cell cycle defect. Radiography 14(2): 144149, 2008. DOI: 10.1016/j.radi.2006.12.001 
11 Trimbos JB, Vergote I, Bolis G, Vermorken JB, Mangioni C, Madronal C, Franchi M, Tateo S, Zanetta G, Scarfone G, Giurgea L, Timmers P, Coens C and Pecorelli S: Impact of adjuvant chemotherapy and surgical staging in early-stage ovarian carcinoma: European organisation for research and treatment of cancer-adjuvant chemotherapy in ovarian neoplasm trial. J Natl Cancer Inst 95(2): 113-125, 2003. PMID: 12529344.

12 Kononen J, Bubendorf L, Kallioniemi A, Barlund M, Schraml P, Leighton S, Torhorst J, Mihatsch MJ, Sauter G and Kallioniemi OP: Tissue microarrays for high-throughput molecular profiling of tumor specimens. Nat Med 4(7): 844-847, 1998. PMID: 9662379.

13 Seidal T, Balaton $\mathrm{AJ}$ and Battifora $\mathrm{H}$ : Interpretation and quantification of immunostains. Am J Surg Pathol 25(9): 12041207, 2001. PMID: 11688582.

14 Kobel M, Kalloger SE, Boyd N, McKinney S, Mehl E, Palmer C, Leung S, Bowen NJ, Ionescu DN, Rajput A, Prentice LM, Miller D, Santos J, Swenerton K, Gilks CB and Huntsman D: Ovarian carcinoma subtypes are different diseases: Implications for biomarker studies. PLoS Med 5(12): e232, 2008. PMID: 19053170. DOI: 10.1371/journal.pmed.0050232

15 Bjersand K, Seidal T, Sundstrom-Poromaa I, Akerud H and Skirnisdottir I: The clinical and prognostic correlation of hrnpm and slc1a5 in pathogenesis and prognosis in epithelial ovarian cancer. PLoS One 12(6): e0179363, 2017. PMID: 28609484. DOI: 10.1371 /journal.pone. 0179363

16 Skirnisdottir I and Seidal T: Association of p21, p21 p27 and p21 p53 status to histological subtypes and prognosis in low-stage epithelial ovarian cancer. Cancer Genomics Proteomics 10(1): 27-34, 2013. PMID: 23382584.

17 Skirnisdottir I, Seidal T and Akerud H: Differences in clinical and biological features between Type I and Type II tumors in FIGO stages I-II epithelial ovarian carcinoma. Int J Gynecol Cancer 25(7): 1239-1247, 2015. PMID: 26035126. DOI: 10.1097/igc.0000000000000484

18 Skirnisdottir IA, Sorbe B, Lindborg K and Seidal T: Prognostic impact of p53, p27, and c-myc on clinicopathological features and outcome in early-stage (FIGO-stages I-II) epithelial ovarian cancer. Int J Gynecol Cancer 21(2): 236-244, 2011. PMID: 21270607. DOI: $10.1097 /$ IGC.0b013e31820986e5

19 Nagle CM, Dixon SC, Jensen A, Kjaer SK, Modugno F, deFazio A, Fereday S, Hung J, Johnatty SE, Fasching PA, Beckmann MW, Lambrechts D, Vergote I, Van Nieuwenhuysen E, Lambrechts S, Risch HA, Rossing MA, Doherty JA, Wicklund KG, Chang-Claude J, Goodman MT, Ness RB, Moysich K, Heitz F, du Bois A, Harter P, Schwaab I, Matsuo K, Hosono S, Goode EL, Vierkant RA, Larson MC, Fridley BL, Hogdall C, Schildkraut JM, Weber RP, Cramer DW, Terry KL, Bandera EV, Paddock L, Rodriguez-Rodriguez L, Wentzensen N, Yang HP, Brinton LA, Lissowska J, Hogdall E, Lundvall L, Whittemore A, McGuire V, Sieh W, Rothstein J, Sutphen R, Anton-Culver H, Ziogas A, Pearce CL, Wu AH and Webb PM: Obesity and survival among women with ovarian cancer: Results from the ovarian cancer association consortium. Br J Cancer 113(5): 817826, 2015. PMID: 26151456. DOI: 10.1038/bjc.2015.245
20 Chen C, Chang YC, Lan MS and Breslin M: [corrigendum] Leptin stimulates ovarian cancer cell growth and inhibits apoptosis by increasing cyclin $\mathrm{d} 1$ and $\mathrm{mcl}-1$ expression via the activation of the mek/erk $1 / 2$ and pi3k/akt signaling pathways. Int J Oncol 49(2): 847, 2016. PMID: 27279381. DOI: 10.3892/ ijo.2016.3564

21 Chen C, Chang YC, Lan MS and Breslin M: Leptin stimulates ovarian cancer cell growth and inhibits apoptosis by increasing cyclin $\mathrm{d} 1$ and mcl-1 expression via the activation of the mek/erk1/2 and pi3k/akt signaling pathways. Int J Oncol 2013 42(3): 1113-1119, 2013. PMID: 23354006. DOI: $10.3892 /$ ijo.2013.1789

22 Diaz ES, Karlan BY and Li AJ: Obesity-associated adipokines correlate with survival in epithelial ovarian cancer. Gynecol Oncol 129(2): 353-357, 2013. PMID: 23402904. DOI: 10.1016/ j.ygyno.2013.02.006

23 Felix AS, Sherman ME, Hewitt SM, Gunja MZ, Yang HP, Cora RL, Boudreau V, Ylaya K, Lissowska J, Brinton LA and Wentzensen N: Cell-cycle protein expression in a populationbased study of ovarian and endometrial cancers. Front Oncol 5: 25, 2015. PMID: 25709969. DOI: 10.3389/fonc.2015.00025

24 Zhang Y, Wu J, Liang JY, Huang X, Xia L, Ma DW, Xu XY and Wu PP: Association of serum lipids and severity of epithelial ovarian cancer: An observational cohort study of 349 chinese patients. J Biomed Res 32(5): 336-342, 2018. PMID: 30249816. DOI: $10.7555 /$ jbr.32.20170096

25 Ogino S, Shima K, Nosho K, Irahara N, Baba Y, Wolpin BM, Giovannucci EL, Meyerhardt JA and Fuchs CS: A cohort study of p27 localization in colon cancer, body mass index, and patient survival. Cancer Epidemiol Biomarkers Prev 18(6): 1849-1858, 2009. PMID: 19505918. DOI: 10.1158/1055-9965.Epi-09-0181

$26 \mathrm{Lu} \mathrm{M}$, Wang Y, Xu F, Xiang J and Chen D: The prognostic of p27(kip1) in ovarian cancer: A meta-analysis. Arch Gynecol Obstet 293(1): 169-176, 2016. PMID: 26198169. DOI: 10.1007/ s00404-015-3817-8

27 Zhao Y, Li Q, Wu X and Chen P: Upregulation of p27kip1 by demethylation sensitizes cisplatin-resistant human ovarian cancer skov3 cells. Mol Med Rep 14(2): 1659-1666, 2016. PMID: 27314502. DOI: $10.3892 / \mathrm{mmr} .2016 .5399$
Received July 4, 2019

Revised July 17, 2019

Accepted July 18, 2019 